\title{
Correction to: Urban Water Management for Future Cities
}

Stephan Köster, Moritz Reese, Jian'e Zuo

\section{Correction to:}

S. Köster et al. (eds.), Urban Water Management for Future Cities, Future City 12, https://doi.org/10.1007/978-3-030-01488-9

The book was inadvertently published with an incorrect author group in chapters 5, 10, and 14. The correct author group is listed below:

Chapter 5 - Fostering Water Treatment in Eutrophic Areas: Innovative Water Quality Monitoring, and Technologies Mitigating Taste \& Odor Problems Demonstrated at Tai Hu - Stephan Küppers, Tim aus der Beek, Wenhai Chu, Bingzhi Dong, Anna Dahlhaus, Henner Hollert, Jianliang Hua, Wei Hua, Yunlu Jia, Lei Li, Holger Lutze, Christian Moldaenke, Yanwen Qin, Wido Schmidt, Christian Staaks, Claudia Stange, Daqiang Yin, Ji Zhao, Binghui Zheng, Linyan Zhu, Hua Zou, and Andreas Tiehm

Chapter 10 - Urban Pipe Assessment Method and Its Application in Two Chinese Cities - Jian'e Zuo, Xiangyang Ye, Xiaoqing Hu, and Zhonghan Yu

Chapter 14 - Cross-boundary Evolution of Urban Planning and Urban Drainage Towards the Water Sensitive "Sponge City" - Meiyue Zhou, Stephan Köster, Jian'e Zuo, Wu Che, and Xianping Wang

The updated versions of the chapters can be found at https://doi.org/10.1007/978-3-030-01488-9_5

https://doi.org/10.1007/978-3-030-01488-9_10

https://doi.org/10.1007/978-3-030-01488-9_14 